\title{
DRUG ADULTERATION IN THE UNITED STATES.
}

By Thomas Stevenson, M.D., and F.R.O.P. Lond.

REOENTLY several prosecutions have been instituted against vendors of adulterated drugs in Massachusetts under the Legislative Act of 1882. In the matter of drugs, the policy of the Massachusetts Board of Health has been to prosecute the manufacturers, who must know what they send into the market, rather than the retailers, who in these days rarely manufacture their own articles, and hence may unwittingly violate the law.

I'wo charges, which may be regarded as test cases, were made against two firms of wholesale druggists in Boston. Tincture of opium was the drug selected as being one of the most important and general in use. Under the Act of 1882, a drug is declared adulterated (1) if, when sold under or by a name recognised in the U.S. Pharmacopœia, it differs from the standard of strength, quality, or purity laid down therein; (2) if, when sold under or by a name, not reeognised in the U.S. Pharmacopœia, but which is found in some other pharmacopœia or other standard work on materia medica, it differs materially from the standard of strength, quality, or purity laid down in such work; (3) if its strength or purity falls below the professed standard under which it is sold. The State Analyst of Drugs found that one of the samples of tincture of opium in question contained only 0.81 per per cent. of morphia instead of 1.2 per cent., according, as he said, to the Pharmacopœia of 1880 ; the other was even more deficient in morphia, containing only 0.72 per cent., or less than twothirds of the prescribed amount.

For the defence, it was in each case asserted that the public issue of the pharmacopœia in October, 1882, was not made till two moriths after the law came into force in the preceding August; and the defendants claimed the right to take any preceding pharmacopceia, even the first one of 1820 , inasmuch as the Act of the Legislature does not specify any particular pharmacopœia. Counsel for the prosecution contended that either the pharmacopœia of 1870 , or that of 1880 , must be in force, and according to the testimony of the State Analyst, Dr. Davenport, one of the compilers of the U.S.P., 1880 , the tinctures fell below the quality of a preparation prepared according to either of these pharmacopœias. Eventually it was ruled that the pharmacopœia of 1880 fixed the standard under which the government could proceed. Practically the change made

* Report of Med. Off. Privy Council ; New Series, No. 8 (1876), p. 130.

† ANALYST, 1883, p, 116. 
in the strength of tincture of opium, as it should be under the pharmacopoeia of 1880, is that the quantity of opium is raised as compared with the pharmacopooia of 1870 , in the proportion of 9 to 10, according to an appendix to the U.S.P.; but according to my calculations, in the proportion of 8 to 9.

The board proved its case against both the firms, but one escaped a conviction on a technical point, and a conviction was obtained in a third case. 'The Boston Druggists' Association is naturally aggrieved, and has, we are told, addressed a remonstrance to the board on its present process, emphasising the propriety of warning a delinquent firm before proceeding against it. It is hardly to be supposed, however, that manufacturing firms can be ignorant of the quality of the goods they send out to the retailers. The Boston Board of Health is doing good service by striking at the fountain head of a pernicious system.

I am indebted for the above facts to an editorial article in The Boston Medical and Surgical Journal. In connection with the above case it is interesting to note the comparative strengths of the U.S.P., 1880, tincture of opium, and that of the B.P. The U.S.P. undergoes decenninal revision, and the issue of 1880 made the material alteration of ordering all preparations to be made by weight. The tincture of opium, U.S.P., 1880, is made by extracting 10 ounces of opium with so much alcohol sp. gr. .92 as is required to make the filtred product weigh 100 ounces. Hence it contains the extractives of exactly 10 per cent. of its weight of opium, or 9.2 parts by weight in 100 by volume. Approximately-for the specific gravity of the tincture must be variable11.9 of an English minim correspond to a grain of opium. It is evident from the above cases that an opium yielding 12 per cent. of morphia is expected to be used in the preparation of the article; whereas the B.P. requires only 6 to 8 per cent. of morphia. If the mean, 7 per cent., be taken, the U.S.P. tincture of opium in a given volume contains nearly twice as much morphia as the B.P. article.

Since Mr. Wynter Blyth's valuable book on "Poisons" is, no doubt, in the hands of many public analysts, it may be well to point out that he states incorrectly the strength of several of the most important opiates. Tineture of opium is stated to be one grain of opium in $14.8 \mathrm{~min}$., i.e. about 6.7 parts by weight in 100 by measure. It should be 1 grain in 14.6 minims, or exactly $7 \cdot 5$ parts by weight in 100 by measure. Ammoniated tincture of opium is stated to contain 1.04 instead of 1.14 parts of opium by weight in 100 by measure. Wine of opium is stated to contain 4.5 instead of 5 ; as it should be of opium extract in $\mathbf{1 0 0}$ parts by measure. Lastly, the extract of opium is said to have its strength about the same as opium itself, whereas good opium yields about half its weight of extract, which should contain practically all the morphia in the opium. A good opium extract should not be less than half as strong again as opium itself.

\section{OHEMICAL NOTES FROM OTHER SOURCES.}

The following paper was sent to us last month, but unfortunately too late for publication. Since then it has appeared in the Pharmaceutical Journal, but as we think that in the present state of matters everything relating to the analysis of milk should appear 
in the ANaLYST, we now present it to our readers, after having been revised and improved by the author:- 